\title{
Comparison of the Drought Stress Responses of Tolerant and Sensitive Wheat Cultivars during Grain Filling: Impact of Invertase Activity on Carbon Metabolism during Kernel Development
}

\author{
Saeed Saeedipour (Corresponding author) \\ Department of Agronomy, Shoushtar Branch, Islamic Azad University, Shoushtar, Iran \\ E-mail: saeeds79@gmail.com
}

Foad Moradi

Agriculture Biotechnology Research Institue, Karaj, Iran

E-mail: foadmoradi@yahoo.com

Received: September 17, 2010 Accepted: October 9, 2010 doi:10.5539/jas.v3n2p32

\begin{abstract}
Developmental changes in the starch and soluble sugars content of flag leaves and grains and the activities enzymes of sucrose metabolism in drought-tolerant (Triticum aestivumL. cv. Zagros) and drought-sensitive with high yielding potential under favorable conditions (cv. Marvdasht) wheat genotypes investigated under controlled water deficit during grain filling. Cultivars were grown in pots and treated with either well-watered (WW) or water-stressed (WS) from anthesis to maturity. WS caused a marked reduction in glucose, fructose and sucrose content of flag leaves and grains of sensitive cultivar. These changes were paralleled by sharp decline in the activity of cell wall invertase and soluble invertase at the both flag leaves and grains of sensitive cultivar. Whereas a transient surge in the activity invertases of flag leaves was found in tolerant cultivar. As the surge in invertase activity faded, in leaves and grains of tolerant cultivar it was replaced by a substantial increase in sucrose synthase activity as seed development proceeds. Notwithstanding increase in sucrose synthase activity in leaves and grains of sensitive cultivar, however this little raises could not be sufficiently active to compensate for decreased levels of invertases and might restrict sucrose export, and together with a concomitant repression in young ovaries, may limit sucrose transport and use and result in partial zygote abortion that led to dramatically reduction in number of kernel and subsequent grain yield under WS treatment in Marvdasht.
\end{abstract}

Keywords: Invertase activity, Sucrose metabolism, Sucrose synthase, Water stress, Triticum aestivum L.

\section{Introduction}

The sensitivity of crops such as wheat (Triticum aestivum L.) to soil drought is particularly important during the grain-filling period because the reproductive phase is extremely sensitive to plant water status (Zinselmeier et al., $1995,1999)$. This is generally accepted that grain-filling rate in cereals is mainly determined by sink strength (Venkareswarlu and Visperas, 1987; Liang et al., 2001). During the grain-filling period of wheat, kernels are very strong sinks for carbohydrate (Ho, 1988; Riffkin et al., 1995). The sink strength can be described as the product of sink size and sink activity (Venkareswarlu and Visperas, 1987). Sink activity is a physiological restraint that includes multiple factors and key enzymes involved in carbohydrate use and storage (Wang et al., 1993). Water stress during early grain filling has a marked effect on grain yield reducing endosperm cell number and thus sink strength which is a product of sink size and the metabolic activity of the sink organ during development (Ho 1988), therefore grain growth during grain filling are determined mainly by factors that operate within or close to the grain itself (Jenner et al., 1991). Biochemical conversion and sucrose-metabolizing is one of the most important components of sink strength and can be determined by the catalytic activities of one or more enzymes involved in this pathway. Uptake in these sinks can occur either directly or through the splitting of sucrose. Plants contain two types of enzymes capable of this splitting: (1) sucrose synthase, which catalyzes a readily reversible reaction; the enzyme appears to be largely cytoplasmic, although it has recently been reported that in some cases it may associate with the cell membrane and be responsible for providing substrates for cell wall synthesis (Ruan et al., 1997), and (2) Sucrose invertase, which catalyzes the irreversible hydrolysis of 
sucrose to glucose and fructose (Copenald 1990). The invertases of higher plants are classified according to their solubility, localization, and optimal $\mathrm{pH}$, and include three types of enzymes: cytoplasmic, vacuolar, and cell wall. Unlike cell wall invertase that is bound to the cell wall, soluble invertase is in the cytosol and/or vacuole and is extractable in the crude supernatant after cell disruption. Xu et al., (1996) reported abundant levels of the two soluble invertases, during the kernel development.

In wheat stems, activities of both sucrose synthase (Wardlaw and Willenbrink, 1994) and acid invertase (Bancal and Triboï, 1993) have been found to be very high at anthesis and to fall sharply during grain filing. The rise in sucrose synthase activity is positively correlated with the onset of starch and storage protein biosynthesis (Obata-Sasamoto and Susuki, 1979), whereas reduced sucrose synthase activity results in a strong decrease of starch accumulation, which is in agreement with the postulated function of sucrose synthase during the storage of sink tissues. In the sink tissues, invertases are associated with developmental processes where their activities are the highest before storage starts (Eschrich, 1980), whereas sucrose synthase is associated with the subsequent storage functions, such as starch synthesis (Heim et al., 1993). While it was originally believed that sucrose synthase was the main determinant of sink strength (Zrenner et al., 1995), measurements on developing tomato fruit suggest that sucrose synthase activity is low in the first week after anthesis, reaching a peak early in development and subsequently declining (Demnitz-King et al., 1997). The peak of sucrose synthase activity occurs when it is postulated that import of sugar into the fruit switches from a predominantly symplastic to an apoplastic mechanism (Patrick, 1997). Evidence is now mounting in the favor of such a role for the extracellular wall-bound invertase, especially during the initial stages of sink development (Roitsch et al., 2000; Roitsch, 1999). Various experimental approaches have been used to demonstrate the importances of this enzyme for assimilate partitioning and determining sink strength. These include inhibition of storage tissue development in carrot roots by antisense repression of cell wall invertase (Tang and Sturm, 1999), arrested seed development in maize mutant lacking cell wall invertase (Miller and Chourey, 1992), kernel abortion in maize when cell wall invertase is suppressed by water stress during pollination (Zinselmeier et al., 1995), induction of sink metabolism in source leaves of transgenic plants by over-expression of a yeast invertase (Stitt and Sonnewald, 1995), and specific expression of a cell wall invertase during pre-storage phase in the thin walled parenchyma of faba bean seed coat (Weber et al.,1995). Not surprisingly, several correlative data suggest a major physiological role for cell wall invertase in maintaining source-to-sink unloading of sucrose and ultimately in determining sink strength. Several studies on the role of cell wall invertase in seed development, especially in establishing the roles of hexoses and sucrose in cell division and storage functions, are reported in Vicia faba (Weber et al., 1996a, 1996b, 1997). In addition to sucrose availability per se, capacity for sucrose use and hexose to sucrose balance may be critically important to zygote development under drought conditions. In general, sucrose levels of stressed ovaries are higher or at least similar to those of non-stressed ovaries (Schussler and Westgate., 1991; Schussler and Westgate., 1995; Zinselmeier et al., 1995), indicating that the capacity to use sucrose may be impaired by drought. Drought stress decreases activities of both vacuolar and cell wall-bound acid invertase during kernel development (Zinselmeier et al., 1995), with parallel reductions in ovary growth and concentration of hexoses. Therefore an understanding of how the involved processes are affected is of particular interest for improving drought tolerance in crops (Boyer, 1996). The objective of this study was to investigate isoforms of invertase and sucrose synthase activity on carbon metabolism in wheat subjected to water deficit during the grain filling stage.

\section{Material and Method}

\subsection{Plant Materials}

The experiment was carried out on the Agricultural Biotechnology Research Institute of Iran $\left(48^{\circ} 20 \mathrm{~N} ; 31^{\circ} 41 \mathrm{E}\right.$; $20 \mathrm{~m}$ above sea level), in the growing season of 2009-2010. Based on preliminary experiments (Saeidi et al, 2006), two contrasting spring wheat cultivars (Triticum aestivum L.) Marvdasht and Zagros (drought susceptible and tolerant during grain filling, respectively were used. Seeds were sown in porcelain pots $(15 \mathrm{~cm}$ in height and $16.5 \mathrm{~cm}$ in diameter) filled with $2.1 \mathrm{~kg}$ of clay-sand-manure $1: 1: 1(\mathrm{v} / \mathrm{v})$, cultivation was performed in a greenhouse with $16 \mathrm{~h}$ supplemental light $\left(300 \mu \mathrm{molm}^{-2} \mathrm{~s}^{-1}\right.$ of photosynthetically active radiation $\left.22^{\circ} \mathrm{C}\right)$ and $8 \mathrm{~h}$ darkness $\left(15^{\circ} \mathrm{C}\right)$, and at 55-60 air humidity. Five uniform plants in each pot were retained after seedling establishment and adequately irrigated with tap water. At three true leaves pots were placed in a field for forty days in order to acclimation to low temperature. The experiment was $2 \times 2$ (two cultivars and two water regimes) factorial design with four treatment. Each of the treatment had four replications with three sub-samples, in a complete randomized block design. Half of the plants of both varieties were exposed to water stress (WS), the imposition of water stress started at anthesis to maturity to reach $50 \%$ field capacity (FC), and in control treatments were maintained as well watered (WW), and were irrigated to reach FC throughout the experiment 
(soil water potential, $\psi$ soil, at -0.01 to $-0.02 \mathrm{MPa}$ ). Water was withheld from treated pots and the soil water content allowed to fall $50 \% \mathrm{FC}$ and the pots then weighed every day. Sufficient water was applied on each time to return the soil moisture to these original levels. In control treatment the soil was status was maintained at FC by weighing the pots daily and adding sufficient water to bring the soil moisture to its original value.

\subsection{Sampling}

Fifteen to twenty plants from each treatment were sampled at 7 and 21 days after anthesis. The flag leaves and the second and third kernel from each spikelet were frozen in liquid nitrogen for $1 \mathrm{~min}$ and stored at $-80{ }^{\circ} \mathrm{C}$ for enzymatic assay. From each treatment twenty plants were harvested at maturity for the determination of grain yield. Each measurement was done on plants from four different treatments.

\subsection{Metabolite Analyses}

All chemicals and enzymes used for the enzymatic measurements were from Sigma Chemical Company (St. Louis, MO, USA). All enzyme assays were optimized for substrate concentration and $\mathrm{pH}$ within the linear phase with respect to incubation time and protein concentration. Protein content was determined according to Bradford (1976), using bovine serum albumin (BSA) as standard. Enzyme activities were expressed as specific activities.

Carbohydrate content was measured after grinding approximately $5 \mathrm{mg}$ of frozen samples (either leaves or kernels) in Eppendorf vials with acid-washed sand and $500 \mu \mathrm{L}$ of $80 \%$ (v/v) ethanol. Material was subsequently heated to $80^{\circ} \mathrm{C}$ for $15 \mathrm{~min}$ and centrifuged for $5 \mathrm{~min}$ at $20,000 \mathrm{~g}$ to pellet insoluble material. Extraction was repeated twice with $500 \mu \mathrm{L}$ of $80 \%$ (v/v) ethanol, and supernatants were pooled for evaporation to dryness in a vacuum centrifuge. Carbohydrates in this fraction were resolubilized in $900 \mu \mathrm{L}$ of water. Reduced sugars were quantified in an aliquot of $100 \mu \mathrm{L}$ according to Nelson (1944) with glucose as a standard. Sucrose was quantified by subtraction using the same methods after sucrose inversion by $\beta$-fructosidase. Complete sucrose hydrolysis was achieved by adding 20 units of $\beta$-fructosidase (Roche Diagnostics, Basel) per sample and incubating for 10 min at $30^{\circ} \mathrm{C}$ in $50 \mathrm{mM}$ sodium acetate buffer with $15 \mathrm{mM}$ magnesium chloride (pH 4.6). The Nelson reducing sugar assay (Nelson, 1944) was also used to estimate starch content after digestion of insoluble material. These fractions were dried in a vacuum centrifuge and boiled for $30 \mathrm{~min}$ with a thermostable amylase (Termamyl, Novo Nordisk, Glostrup, Denmark) in $1 \mathrm{~mL}$ of $5 \mathrm{~mm}$ sodium dihydrogen phosphate buffer (pH 6.0). Starch was further hydrolyzed in a $100-\mu \mathrm{L}$ aliquot with 2.5 units of amyloglucosidase (Roche Diagnostics) in $50 \mathrm{mM}$ sodium acetate buffer with $15 \mathrm{mM}$ magnesium chloride $\left(\mathrm{pH} \mathrm{4.6)}\right.$ at $65^{\circ} \mathrm{C}$. Sample blanks, reagent blanks, and samples with known starch content were included. Three samples from each date and treatments were analyzed.

\subsection{Enzymatic Activity}

Crude enzyme extracts from approximately $50 \mathrm{mg}$ of frozen leaf or grain material were further ground in Eppendorf vials with sand and $300 \mu \mathrm{L}$ of extraction buffer consisting of $50 \mathrm{mM}$ HEPES-NaOH, $1 \mathrm{mM}$ EDTA, and $2.5 \mathrm{mM}$ dithiothreitol, (DTT) $\mathrm{pH}$ 7.0. Samples were centrifuged for $10 \mathrm{~min}$ at 20,000g to pellet insoluble material. The soluble protein extract was removed, and the remaining pellet was washed three times with extraction buffer. Insoluble proteins were then extracted with buffer containing $1 \mathrm{M} \mathrm{NaCl}$ (Doehlert and Felker, 1987). Soluble protein extract $(200 \mu \mathrm{L})$ was dialyzed against extraction buffer for $16 \mathrm{~h}$ at $0^{\circ} \mathrm{C}$ on a 10,000 molecular weight cutoff dialysis membrane (Pierce, Rockford, IL) to remove endogenous soluble carbohydrates. The concentration of total protein was measured in the extract as described by Bradford (1976) using a bovine serum albumin (BSA) standard.

Activities of soluble and insoluble invertase were measured as described by Tsai et al., (1970) with minor modifications. Soluble (vacuole acid and neutral cytosol) and insoluble invertase extracts (10 or $20 \mu \mathrm{L})$ were assayed in a total volume of $300 \mu \mathrm{L}$, with an assay buffer containing $50 \mathrm{mM}$ sodium acetate, $15 \mathrm{mM}$ magnesium chloride, and $100 \mathrm{mM}$ sucrose $(\mathrm{pH} 4.5)$. Assays were incubated for 0.5 to $2 \mathrm{~h}$ at $30^{\circ} \mathrm{C}$, with blanks terminated immediately after addition of protein extracts. All reactions were terminated by adding $300 \mu \mathrm{L}$ of Nelson's No. 1 reagent. Reduced sugars were quantified by spectrometry according to the Nelson- Somogyi method (Nelson, 1944) with a glucose standard.

A modified method for sucrose synthase (SS) extraction was used (Ranwala and Miller 1998) $50 \mathrm{mg}$ of frozen leaf or grain material were homogenized with a mortar and pestle ( $5 \mathrm{ml}$ buffer per $1 \mathrm{~g} \mathrm{FW})$ in $100 \mathrm{mM}$ Hepes (pH 7.5) containing $10 \mathrm{mM}$ isoascorbate, $3 \mathrm{mM} \mathrm{MgCl} 2,5 \mathrm{ml}$ DTT, $2 \mathrm{ml}$ EDTA, 5\% (v/v) glycerol, 3\% (w/v) PVPP, and $0.01 \%$ Triton X-100. After centrifugation at $15,000 \mathrm{~g}$ for $30 \mathrm{~min}$, the supernatant was desalted on a Sephadex G-25 column and the proteins were eluted by the reaction buffer, which contained $50 \mathrm{mM}$ Hepes (pH 7.5), $10 \mathrm{mM} \mathrm{MgCl}_{2}, 2 \mathrm{mM}$ EDTA, and $3 \mathrm{mM}$ DTT. Sucrose synthase activities (in the synthesis direction) were determined as described by Wardlaw and Willenbrink (1998) and expressed as 1 mol sucrose synthesized per mg protein per $h$. 


\subsection{Statistical analysis}

All data were analyzed for variance using the SAS statistical analysis package (version 6.12; SAS Institute, Cary, NC, USA). Data from each sampling were analyzed separately. Means were tested by least significant difference at $P \quad 0.05$ level (LSD 0.05). Liner regression was used to evaluate the relationships of starch and sucrose-metabolizing enzyme activities in the grain.

\section{Results}

\subsection{Changes in Soluble Sugars on leaves and grains}

Ethanol soluble carbohydrate (ESC) containing glucose, fructose of well-watered plants increased from (7 to 21) DAA at both cultivars. However glucose and fructose accumulation was bigger in Marvdasht than Zagros, the values raised by 4.7 and 4.2 time for glucose and fructose respectively in Marvdasht compare to 2.4 and 2.3 time during (7 to 21) DAA in Zagros (Fig.1A-B). Under water stress treatments, at both cultivars, glucose and fructose decreased significantly, but the loss was more in Marvdasht and decreased by 55.75 for glucose and $46.9 \%$ for fructose, contrast to 17.6 and 19.95 , respectively in Zagros during the 21 days from anthesis (Fig. 1A-B).

Sucrose concentration in the leaves of both cultivars sharply increased during the 3 weeks from anthesis, and was enhanced by the water stress in Zagros but decreased dramatically during the same period in Marvdasht cultivar (Fig.1C).

Opposite to that observed in the leaves of the cultivars, the glucose and fructose in grains sharply decreased during (7 to 21) DAA under well-watered. The water stress treatment substantially reduced glucose and fructose during the 7 days from anthesis but there after (21 DAA), both carbohydrate little increased in Zagros and decreased significantly in Marvdasht cultivar (Fig. 3A-B). A similar changing pattern was observed for sucrose concentration in the grains from 7 to 21 DAA (Fig. 3C). During 7 days from anthesis in both cultivars sucrose concentration decreased significantly by the water stress but after 21 days from anthesis sucrose was reduced $32 \%$ compare to control treatment in Marvdasht and no change observed in Zagros cultivar.

\subsection{Changes in Starch in the leaves and grains}

The starch contents in leaves of both cultivars were strongly affected by the water stress. However, the accumulation pattern of starch varied by the time (Fig.1D). After 7 days from anthesis starch in leaves reduced to 100 and $35.7 \%$ in Marvdasht and Zagros cultivars respectively, in water deficit compare to well water, but thereafter (two week later) substantially increased observed in both cultivar, specially in Zagros about to 300\% compare to $25 \%$ in Marvdasht under water stress (Fig. 1D).

Starch concentration in the grains was sharply increased during (7 to 21 DAA) nearly to 2 and 2.5 fold in Zagros and Marvdasht, respectively in well-watered treatment (Fig. 3D). Water deficit greatly reduced starch and the loss was more in Marvdasht cultivar after 21 days from anthesis (Fig. 3D).

\subsection{Enzyme activities on leaves}

The activity of four enzymes involved in sucrose conversion in wheat exhibited variable responses with time and water availability. Sucrose synthase activity in well water leaves was decreased from 7 to 21 DAA in both cultivars. It was substantially enhanced by water stress during the first 7 days after withholding water, and then remained at high activity in Zagros whereas greatly declined in Marvdasht after 21 days of water stress (Fig. 2D). Irrespective of well water and water stress treatments, sucrose synthase activity in leaves of Zagros was more than Marvdasht cultivar (Fig. 2D). Activities of both soluble and insoluble acid invertase in the leaves of water stress cultivars were decreased by time, with the exception of acid invertase in Marvdasht cv. (Fig. 2A-C). Very similar changing pattern to sucrose synthase activity, acid invertase activities in Zagros cv. was markedly increased in water stress leaves, and stayed at high level throughout the 21 days after withholding water (Fig. 2A), while bound and alkaline invertase, dramatically enhanced during the first 7 days after water stress, and decreased afterward to the well water level or more than it with bound and alkaline invertase respectively in Zagros cv. (Fig. 2B-C). Unlike the changing pattern of enzyme activities in Zagros cv. they were sharply decreased in Marvdasht by water stress after 21 days from stress, except of alkaline invertase which a little increased during ( 7 to 21 DAA) ( Fig. 2A-C).

\subsection{Enzyme activities in grains}

Sucrose synthase activities in the grains irrespective of well water and water stress treatments, elevated by the time in both cultivars. In comparison, the sucrose synthase activity was enhanced more in Zagros than Marvdasht when the water stress imposed (Fig. 4D). At the well-water treatment, sucrose synthase activities were always the same in both cultivars during 21 days DAA. 
Regardless of water deficit a similar changing pattern in soluble and insoluble invertase activities observed in both cultivars by the time ( 7 to 21) DAA (Fig. 4A-C), however under water stress condition they were sharply decreased, with soluble invertase reduced more than insoluble invertase. Sucrose synthase activity, on a per grain basis, was much higher than those of acid invertase during the fast accumulation period of starch in the kernel 7 to 21 DAA (Fig. 4A-D), indicating that sucrose synthase is a predominant enzyme responsible for sucrose cleavage in wheat grain.

\subsection{Invertase Activities and Hexose/Sucrose Balance}

The regression analysis in Fig. 5 (A-C) confirms a close relation between hexose to sucrose ratio and insoluble and soluble invertase activity in grains. However, the correlation was much more $\left(r^{2}=0.92 * * *\right)$ for insoluble invertase contrast to cytosolic $\left(r^{2}=0.77^{* *}\right)$ and acid invertase $\left(r^{2}=0.64^{* *}\right)$ activity. The correlation between hexose to sucrose ratio and activity of soluble and insoluble invertase observed here demonstrate the involvement of symplastic and epoplastic path for sugar movement in young kernels.

\subsection{Correlation between enzyme activity and $\mathrm{NSC}_{S}$ in flag leaf}

The correlation between insoluble invertase and starch negative and statistically significant $(\mathrm{r}=-0.64 * *, \mathrm{p}<0.01$, Table 1). No significant correlation was observed between other enzymes and starch (Table 1). The result showed that the correlation of sytosolic invertase and sucrose synthase was much higher with glucose and fructose than those of both insoluble and soluble acid invertase.

\subsection{Grain yield}

The final grain yield under well water treatment was significantly different between two cultivars and was markedly more in Marvdasht than Zagros cv. The water stress treatments significantly reduced grain yield in Marvdasht while was not affected on Zagros grain yield (Fig. 6). Suggesting the enzymatic activities may play an important regulative role in existence of discernible difference between cultivars.

\section{Discussion}

Starch accumulate in leaves as a temporary reserve form of carbon in the leaves and is the principal component of dry mass accumulated in mature leaves, whereas sucrose is transported to different organs it is used by plants. During periods of active photosynthesis, excess carbohydrates produced are temporarily stored as starch in the leaves for subsequent remobilization to other developing tissue when there is little or no photosynthesis (Basu and Minhas, 1991; Lorenzen and Ewing, 1992). Our result showed that sucrose and starch accumulated in leaves of sensitive cultivar due to higher rate of photosynthesis (Saeidi et al, 2006), more than resistances one under well water condition but not under water stress treatment (Fig. 1C-D). We found that water stress resistant cultivar also contained higher levels of acid and bound invertase accompanied sucrose synthase activity in the leaves than the sensitive one (Fig. 2A-B), indicating that sucrose degradation was increased in water stress resistant cultivar leaves. A similar observation was made in potato cells (Wang et al., 2000). It is believed that the continual cycling of its degradation and synthesis is one of the common features of sucrose metabolism in many plant systems (Geigenberger and Stitt 1991, 1993; Hill and Rees 1995). The enhanced activities of sucrose synthase, acid and bound invertase in the leaves of water stress of tolerant cultivar may contribute to the a rapid cycling of sucrose, thus promoting carbon partitioning in favor of sucrose accumulation for counteracting the stress condition (Wang et al., 2000). On basis of our results glucose, fructose, and sucrose concentration in the flag leaves of sensitive cultivar significantly decreased to $55.7,46.9$ and $37 \%$ respectively, resulting in remarkable reduction in acid and bound invertase activity after 21 days from water deficit contrast to resistant cultivar just 18.8 and $20.3 \%$ for glucose and fructose but opposite to sensitive cultivar a more pronounced increase (104\%) in sucrose concentration of resistant cultivar observed ( Fig.1 A-C) that coincide with more in soluble and insoluble invertase activity (Fig. 2A-B).

It is worth noting that there were not significantly different in reducing and non reducing sugars on leaves between two the cultivars under water stress treatment (Fig. 1A-C). These events mark a turning point in the biochemical and physiological status of the both cultivars upon impose water stress. This change in the activity of invertase a key marker of discrepancies between cultivars that led to disruption of transporting system and restrict current assimilation and remobilization of reserves stored in the leaves of sensitive cultivar.

It was hypothesized that high levels of enzymes involved in the breakdown of sucrose in the sinks would increase sink capacity by lowering the local concentration of sucrose, thereby generating a gradient that allows further unloading of sucrose from phloem (Wardlaw, 1968; Liang et al., 2001). Since both sucrose synthase and invertase are involved in sucrose cleavage in sink tissue, their activities are regarded as biochemical markers of sink strength (Wang et al., 1993; Ranwala and Miller, 1998). 
Our results showed that the activity of soluble and insoluble invertase restricted much higher by time and water deficits than well-watered treatment in grain (Fig.4 A-C), whereas sucrose synthase activities in grains were higher under water deficits in both cultivars with obviously further activity in Zagros cv. (Fig. 4D). Drought stress has been found to consistently affect sugar metabolism and decrease activities of soluble and insoluble invertases (Zinselmeier et al., 1995, 1999). We conclude that in addition to the direct effect of sucrose in osmotic adjustment, the enhanced activities of sucrose synthase in the grains of Zagros cv. contributed to the increased assimilates to grains under water deficits. Interestingly, greatly increases in sucrose synthase was observed in tolerant cultivar than sensitive one by water stress which suggests that falls in soluble and insoluble levels are physiologically compensated for by rises in sucrose synthase in this cultivar. In comparison, the main reasons led to elevate grain yield in Marvdasht under well water returned to 1) The activity of vacuolar invertase that reach to more than 2 fold the amount of Zagros and sharply reduced by water deficit 2) The high level activities of bound invertase in well water condition, that greatly restricted by water stress too (Fig. 4A-B). A vacuolar invertase path for sucrose hydrolysis would be especially useful in a symplastically continuous system of phloem-unloading and post-phloem transport where internal sucrose cleavage could sustain sucrose gradients across plasmodesmata (Duke et al., 1991; Sturm et al., 1995; Fisher and Cash-Clark, 2000; Kim et al., 2000).

A central role has been implicated for hexose to sucrose balance in regulating key aspects of ovary and seed development (Weber et al., 1996, 1998; Wobus and Weber, 1999; Weschke et al., 2000). In the present study, the hexose to sucrose ratio was correlated to activity of soluble and very closely correlation to insoluble invertase $(p=0.92)$, in grains (Fig. 5A-C) indicating importance of this enzymes in sucrose cleavage in seed development. In developing grains, like many other fruits, sucrose transport and metabolism thus occur largely in the symplast of maternal tissues that predominate in the young ovaries. In our study the correlation between hexose to sucrose ratio and activity of invertases observed here is compatible with a predominantly apoplectic and then symplastic path for sugar movement in kernels (Fig. 5A \& C).

The authors suggested that low activity of acid invertases (soluble and bound cell) might contribute to the observed reductions of starch biosynthesis in sensitive cv. (Fig. 3D) They further noted that depletion of these starch reserves, together with the reduced sucrose supply under water stress (Fig. 3C), could probably be lethal for the newly formed zygote in sensitive cultivar which needs further investigations.

\section{Conclusion}

Research presented here provides significant insight into our understanding of early stages in grain development, into their marked sensitivity to stress, and also into the regulation and roles of different invertase activity during these formative periods. Our results demonstrate that an accurate assessment of the sensitivity of a genotype to drought stress, the responses of the whole plant, including the vegetative and reproductive organs must be taken into consideration. We found that the continuously high invertases and sucrose synthase activities in flag leaves and grains respectively, induced by water deficit, are responsible for yield stability in tolerant cultivar. Hence, acid and bound cell invertase activity levels, before or immediately after pollination indicates distinct contributions to alleviate harmful effects of drought stress.

\section{Acknowledgement}

The corresponding author gratefully acknowledges the funding from the Islamic Azad University, Shooshtar branch through Grant.

\section{References}

Bancal, P., \& Triboï, E. (1993). Temperature effect on fructan oligomer contents and fructan-related enzyme activities in stems of wheat (Triticum aestivum L.) during grain filling. New Phytology, 123, 247-253.

Basu, P.S. \& Minhas, J.S. (1991). Heat tolerance and assimilate transport in different potato genotype. Journal of Experimental Botany, 42, 861-866.

Boyer, J.S. (1996). Advances in drought tolerance in plants. Advance in Agronomy, 56, 187-218.

Bradford, M, M. (1976). A rapid and sensitive method for the quantitation of microgram quantities of protein utilizing the principle of protein-dye binding. Annual Biochemistry, 72, 248-254.

Copenald, L. (1990). Enzyme of sucrose metabolism. Methods Plant Biochemistry, 3, 73-85.

Demnitz-King, A., Ho, L.C. \& Baker, D.A. (1997). Activity of sucrose hydrolysing enzymes and sugar accumulation during tomato fruit development. Plant Growth. Regulator, 22, 193-201.

Doehlert, D.C. \& Felker, F.C. (1987). Characterization and distribution of invertase activity in developing maize (Zea mays L.) kernels. Plant Physiology, 70, 51-57. 
Duke, E.R., McCarty, D.R. \& Koch, K.E. (1991). Organ-specific invertase deficiency in the primary root of an inbred maize line. Plant Physiology, 97, 523-527.

Eschrich, W. (1980). Free space invertase, its possible role in phloem unloading. Berichte der Deutschen Botanischen Gesellschaft, 93, 363-378.

Fisher, D.B. \& Cash-Clark, C.E. (2000). Gradients in water potential and turgor pressure along the translocation pathway during grain filling in normally watered and water-stressed wheat plants. Plant Physiology, 123, $139-147$.

Geigenberger, P. and Stitt, M. (1991). A "futile" cycle of sucrose synthesis and degradation is involved in regulating partitioning between sucrose, starch and respiration in cotyledons of germinating (Ricinus communis L.) seedlings when phloem transport is inhibited. Planta, 185, 81-90.

Geigenberger, P. \& Stitt, M. (1993). Sucrose synthase catalyses a reversible reaction in vivo in developing potato tubers and other plant tissues. Planta, 189, 329-339.

Heim, U., Weber, H., Baumlein, H. \& Wobus, U. (1993). A sucrose synthesis gene of Vicia faba L.: Expression pattern in developing seeds in relation to starch synthesis and metabolic regulation. Planta. 191, 394-401.

Hill, S.A. \& Rees T. (1995). The effect of glucose on the control of carbohydrate metabolism in ripening bananas. Planta, 196, 335-343.

Ho, L.C. (1988). Metabolism and compartmentation of imported sugars in sink organs in relation to sink strength. Annul Review of plant physiology and plant Molecular Biology, 39, 355-378.

Jenner, C.F., Ugalde, T.D. \& Aspinal, D. (1991). The physiology of starch, protein depodition in endosperm of wheat. Australian Journal of. Plant Physiology, 18, 211-226.

Kim, J.Y., Mahe,' A., Brangeon, J. \& Prioul, J.L. (2000). A maize vacuolar invertase, IVR2, is induced by water stress: organ/tissue specificity and diurnal modulation of expression. Plant Physiology, 124, 71-84.

Liang, J., Zhang, J. \& Cao, X. (2001). Grain sink strength may be related to the poor grain filling of indica-japonica rice (Oriza sativa L.) hybrids. Plant Physiology, 112, 470-477.

Lorenzen, J.H. \& Ewing, E. (1992). Starch accumulation in leaves of potato (Solanum tuberosum L.) during the first 18 days of photoperiod treatment. Annul of Botany, 69,481-485.

Mathias, N. A., Asch, F., Wu, Y., Richardt, J. C., Næsted, H., Overgaard, M. V. \& Elaine, K. K. (2002). Soluble invertase expression is an early target of drought stress during the critical, abortion-sensitive phase of young ovary development in maize. Plant Physiology, 130, 591-604.

Miller, M.E. \& Chourey, P.S. (1992). The maize invertase-deficient miniature-1 seed mutation if associated with aberrant pedicle and endosperm development. The Plant Cell, 4, 297-305.

Nelson, N. (1944). A photometric adaptation of the Somogyi method for the determination of glucose. Journal of Biological.Chemeistry, 153, 375-380.

Obata-Sasamoto, H. \& Suzuki, H. (1979). Activities of enzymes relating starch synhesis and endogenous levels of growth regulators in potato stolen tips during tuberization. Physiology of Planta, 45, 320-324.

Patrick, J.W. (1997). Phloem unloading: sieve elements unloading and post sieve element transport. Annual Review of Plant Physiology and Plant Mollecular Biology, 48, 191-122.

Ranwala, A.P. \& Miller, W.B. (1998). Sucrose-cleaving enzymes and carbohydrate pool in Lilium longiflorum floral organ. Plant Physiology, 103, 541-550.

Riffkin, H.L., Duffus, C.M. \& Bridges, IC. (1995). Sucrose metabolism during development in wheat ( Triticum aestivum L.). Plant Physiology, 93,123-131.

Roitsch, T., Goetz, M., Ehneß, R., Hause, B., Hofmann, M. \& Sinha, A.K. (2000). Regulation and function of extracellular invertase from higher plants in relation to assimilate partitioning, stress responses and sugar signaling. Australian Journal of Plant Physiology, 27, 815-825.

Roitsch, T. (1999). Source-sink regulation by sugars and stress. Current Opinion in Plant Biology, 2,198-206.

Ruan, Y.L., Chourey, P.S., Delmer, D.P. \& Perez-Grau, L. (1997). The differential expression of sucrose synthase in relation to diverse paterns of carbon partitioning in developing cotton seed. Plant Physiology, 115, 375-385. 
Saeidi, M., F. Moradi, A. Ahmadi, K. Poostini and G. Najafian. (2006). Effect of exogenous application of ABA and CK at different stages of grain development on some physiological aspects of source and sink relationship in two bread wheat cultivars. Iranian Journal of Crop Sciences, 8, 268-282.

Schussler, J.R. \& Westgate, M.E. (1991). Maize kernel set at low water potential: II. Sensitivity to reduced assimilates at pollination. Crop Science, 31, 1196-1203.

Schussler, J.R. \& Westgate, M.E. (1995). Assimilate flux determines kernel set at low water potential in maize. Crop Science, 35, 1074-1080.

Stitt, M. \& Sonnewald, U. (1995). Regulation of metabolism in transgenic plants. Annul Review of plant physiology and plant Molecular Biology, 46, 341-368.

Sturm, A., Sebkova, V., Lorenz, K., Hardegger, M., Lienhard, S. \& Unger, C. (1995). Development- and organ-specific expression of the genes for sucrose synthase and three isoenzymes of acid $\beta$-fructofuranosidase in carrot. Planta, 195, 601-610.

Tang, G. \& Sturm, A. (1999). Antisense repression of vacuolar and cell wall invertase in transgenic carrots alters early plant development and sucrose partitioning. The plant Cell, 11, 177-189.

Tsai, C.Y., Salamini, F. \& Nelson, O.E. (1970). Enzymes of carbohydrate metabolism in the developing endosperm of maize. Plant Physiology, 46, 299-306.

Venkateswarlu, B. \& Visperas, R.M. (1987). Source-sink relationship in crop plants. International Rice Research Paper Series, 125, 1-19.

Wang, F., Sanz, A., Brenner, M.L. \& Smith, A. (1993). Sucrose synthase, starch accumulation, and tomato fruit sink strength. Plant Physiology, 101, 321-327.

Wang, H.L., Lee, P.D., Chen, W.L., Huang, D.J. and Su, J.C. (2000). Osmotic stress-induced changes of sucrose metabolism in cultured sweet potato cells. Journal of Experimental Botany, 51, 1991-1999.

Wardlaw, I.F. \& Willenbrink, J. (1994). Carbohydrate storage and mobilization by the culm of wheat between heading and grain maturity: the relation to sucrose synthase and sucrose-phosphate synthase. Australian Journal of Plant Physiology, 21, 255-271.

Wardlaw, I.F. (1968). The control and pattern of movement of carbohydrates in plants. Botany Review, 34, 79-105.

Weber, H., Borisjuk, L., Heim, U., Buchner, P. \& Wobus, U. (1995). Seed coat-associated invertase of faba bean control both unloading and storage functions; Cloning of cDNAs and cell type-specific expression. The Plant Cell, 7, 1835-1846.

Weber, H., Borisjuk, L., Heim, U., Sauer, N. \& Wobus, U. (1997). A role for sugar transporters during seed development: molecular characterization of a hexose and a sucrose carrier in faba bean seeds. Plant Cell, 9, 895-908.

Weber, H., Borisjuk, L. \& Wobus, U. (1996a). Controlling seed development and seed size in Vicia faba: a role for seed coat-associated invertases and carbohydrate state. Plant Journal, 10, 823-830.

Weber, H., Buchner, P., Borisjuk, L. \& Wobus, U. (1996b). Sucrose metabolism during cotyledon development of (Vicia faba L.) is controlled by the concerted action of both sucrose-phosphate synthase and sucrose synthase: expression patterns, metabolic regulation and implications for seed development. Plant Journal, 9, 841-850.

Weber, H., Heim, U., Golombek, S., Borisjuk, L., Manteuffel, R. \& Wobus, U. (1998). Expression of a yeast-derived invertase in developing cotyledons of Vicia narbonensis alters the carbohydrate state and affects storage functions. Plant Journal, 16, 163-172.

Weschke, W., Panitz, R., Sauer, N., Wang, Q., Neubohn, B., Weber, H. \& Wobus, U. (2000). Sucrose transport in barley seeds: molecular characterization of two transporters and implications for seed development and starch accumulation. Plant Journal, 21, 455-467.

Willenbrink, J., Bonnett, G.D., Willenbrink, S. \& Wardlaw, I.F. (1998). Changes of enzyme activities associated with the mobilization of carbohydrate reserves (fructans) from the stem of wheat during kernel filling. New Phytology, 139, 471-478.

Wobus, U. \& Weber, H. (1999). Sugars as signal molecules in plant seed development. Biological Chemistry, 380, 937-944. 
Xu, J., Avigne, W.T., McCarty, D.R. \& Koch, K.E. (1996). A similar dichotomy of sugar modulation and developmental expression affects both paths of sucrose metabolism: evidence from a maize invertase gene family. Plant Cell, 8, 1209-1220.

Zinselmeier, C., Jeong, B.R. \& Boyer, J.S. (1999). Starch and the control of kernel number in maize at low water potentials. Plant Physiology, 121, 25-35.

Zinselmeier, C., Westgate, M.E., Schussler, J.R. \& Jones, R.J. (1995). Low water potential disrupts carbohydrate metabolism in maize (Zea mays L.) ovaries. Plant Physiology, 107, 385-391.

Zrenner, R., Salanoubat, M., Willmitzar, L. \& Sonnewald, U. (1995). Evidence of the crucial role of sucrose synthase for sink strength using transgenic potato plants (Solanum tuberosum L.). Plant Journal, 7, 97-107.

Table 1. Correlations of sucrose-metabolizing enzyme activities with the non-structural carbohydrates (NSCs) concentration in flag leaves

\begin{tabular}{|l|l|l|l|l|}
\hline Correlation with: & Glucose & Fructose & Sucrose & Satrch \\
\hline Acid Inv. & 0.10 & 0.01 & 0.34 & 0.08 \\
\hline Bound Inv. & -0.25 & $-0.35^{*}$ & -0.34 & $-0.64^{* *}$ \\
\hline Alkalin Inv. & $-0.54^{* * *}$ & $-0.57^{* *}$ & $-0.38^{*}$ & -0.25 \\
\hline SuSase & $-0.53^{* * *}$ & $-0.56^{* * *}$ & -0.27 & -0.22 \\
\hline
\end{tabular}

*, ** Indicate correlation significance at $P=0.05$ and $P=0.01$ levels, respectively.
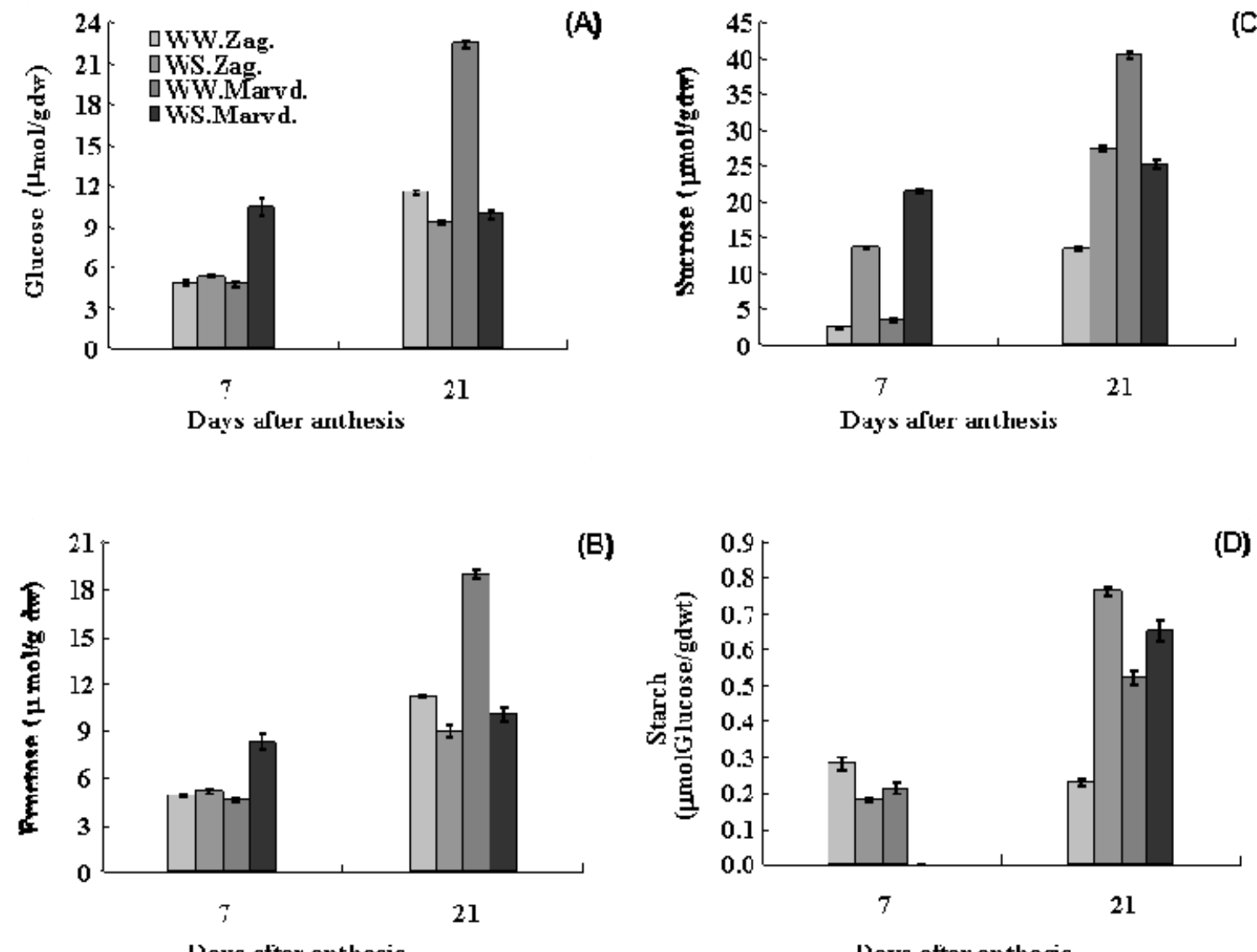

(B)

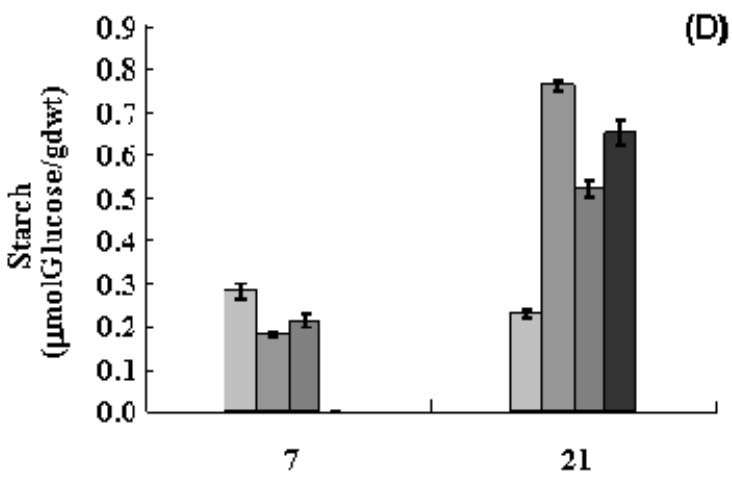

Days after anthesis

Days atter anthesis

Figure 1. Changes in concentrations of nonstructural carbohydrates, Glucose (A), Fructose (B), Sucrose (C) and

Starch (D), in well-watered (WW) and water-stressed (WS) in flag leaves during grain filling in two wheat cultivars (drought Sensitive cv. Marvdasht and drought Tolerant cv. Zagros). Vertical bars represent \pm SE of the mean $(n=3)$ 

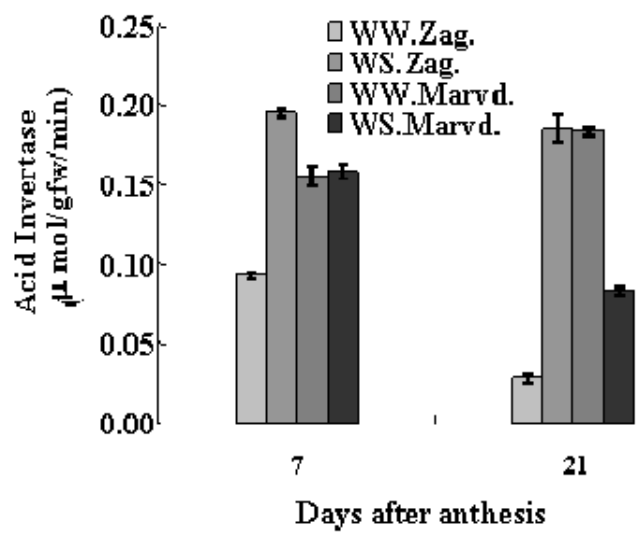

(A)
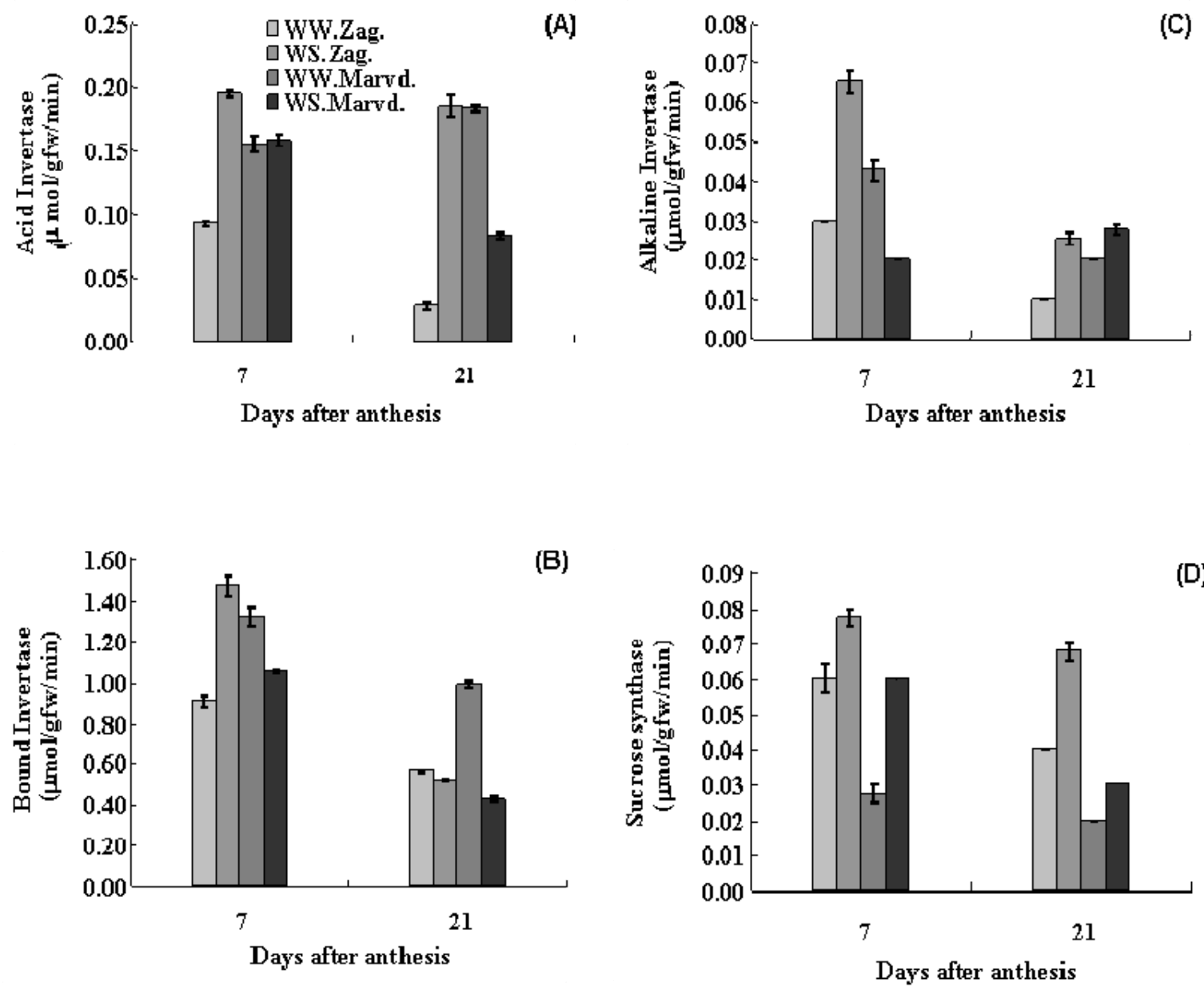

Figure 2. Changes of activities of Acid Invertase (A), Bound cell Invertase (B), Alkaline Invertase (C) and Sucrose Synthase (D), in well-watered (WW) and water-stressed (WS) in flag leaves during grain filling in two wheat cultivars (drought sensitive cv. Marvdasht and drought Tolerant cv. Zagros). Vertical bars represent \pm SE of the mean $(n=3)$ 

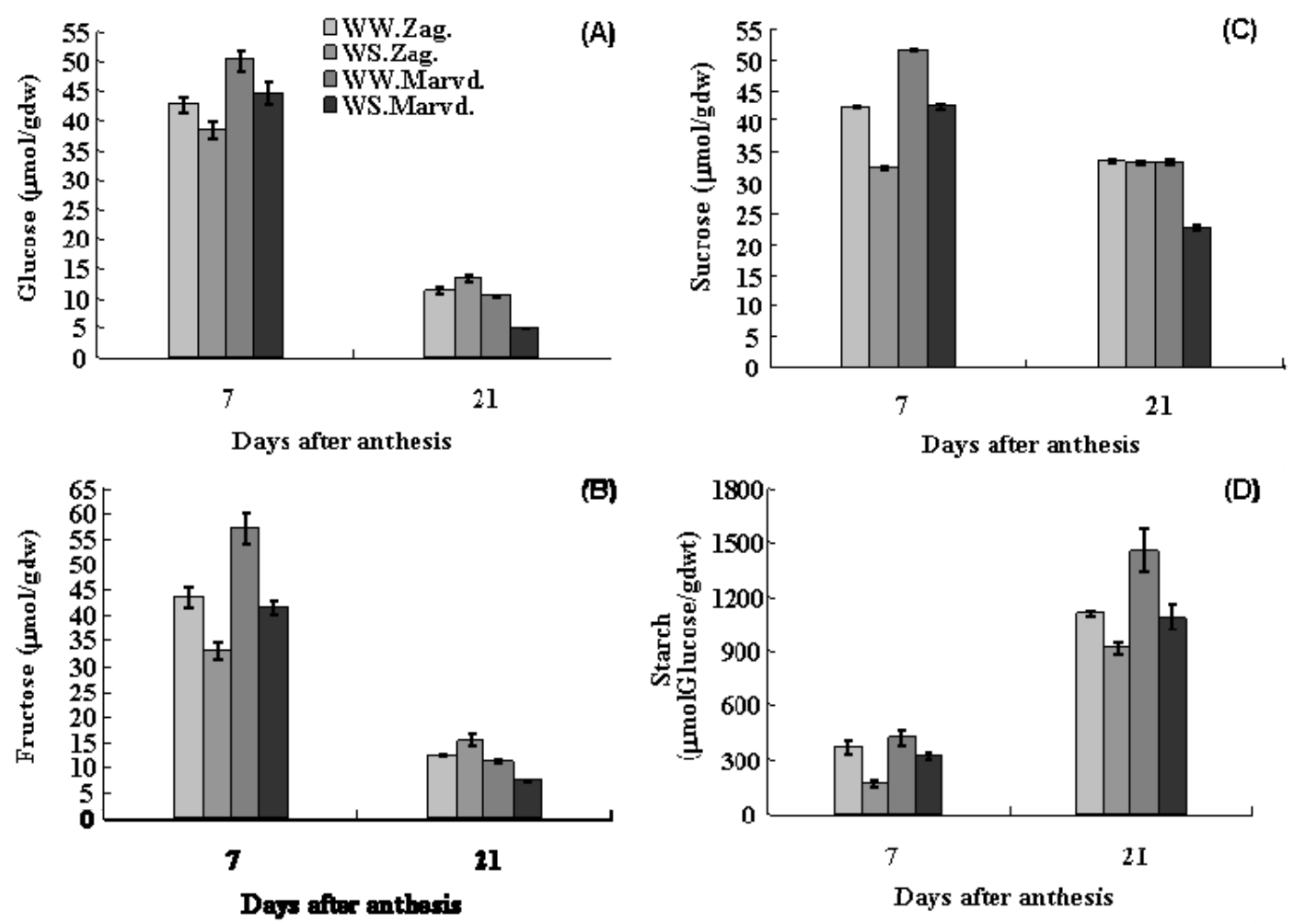

Figure 3. Changes in concentrations of nonstructural carbohydrates, Glucose (A), Fructose (B), Sucrose (C), and Starch (D), in well-watered (WW) and water-stressed (WS) in grains during grain filling in two wheat cultivars (drought Sensitive cv. Marvdasht and drought Tolerant cv. Zagros). Vertical bars represent $\pm \mathrm{SE}$ of the mean $(n=3)$
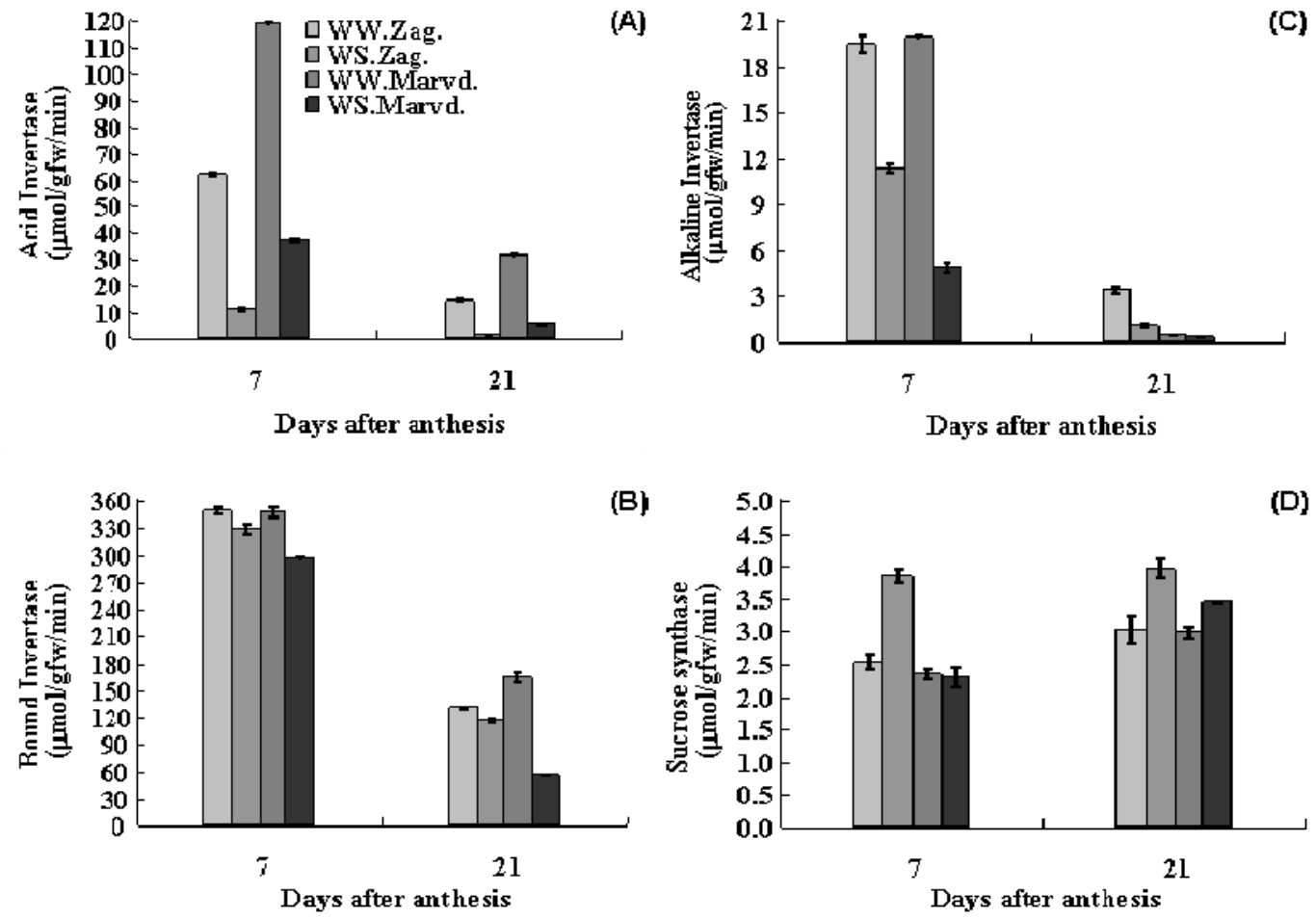

Figure 4. Changes of activities of Acid Invertase (A), Bound cell Invertase (B), Alkaline Invertase (C) and Sucrose Synthase (D), in well-watered (WW) and water-stressed (WS) in grains during grain filling in two wheat cultivars (drought sensitive cv. Marvdasht and drought Tolerant cv. Zagros). Vertical bars represent \pm SE of the mean $(n=3)$ 

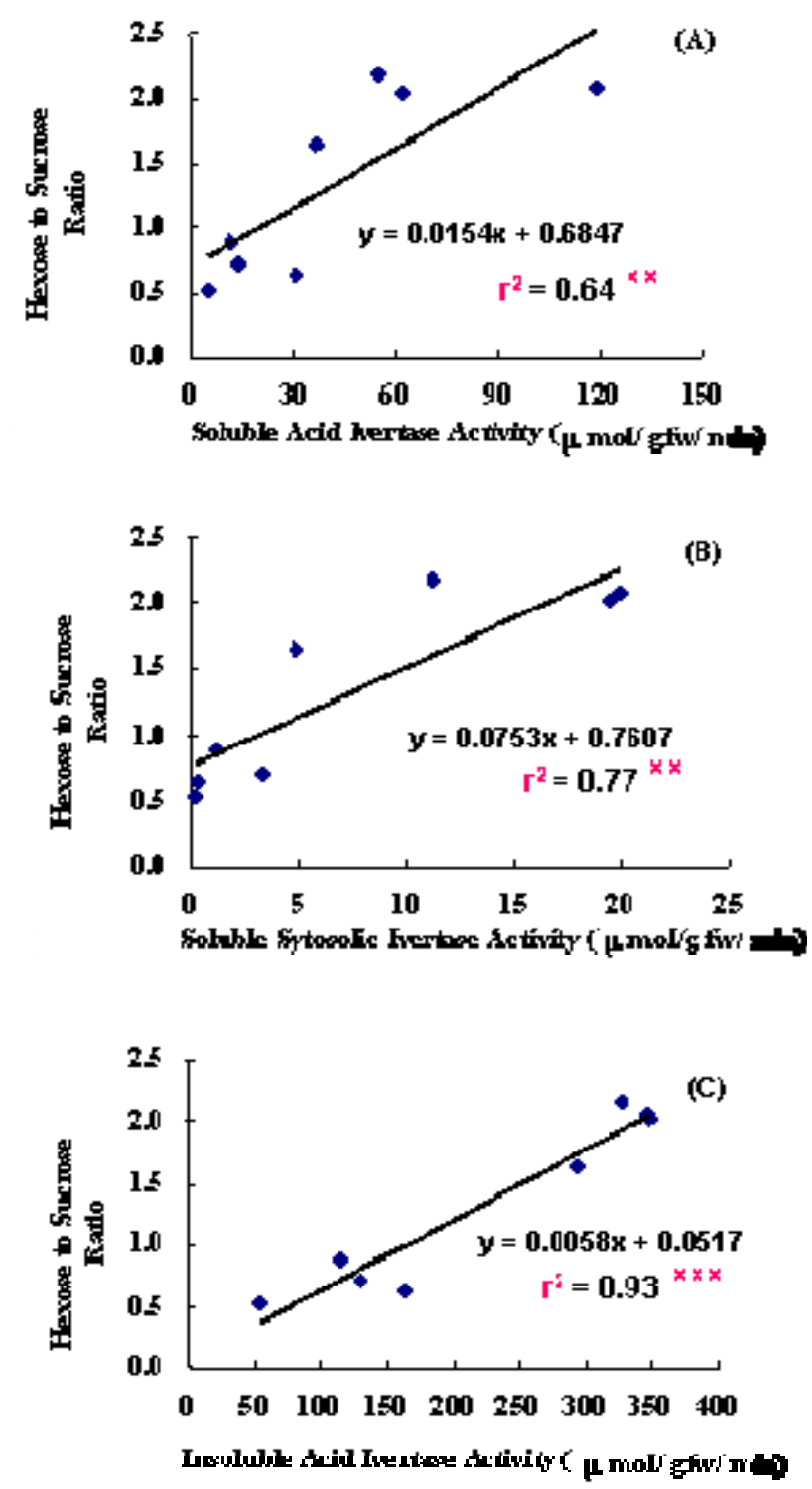

Figure 5. The correlation between the hexose to Suc ratio (w/w) and Acid Invertase (A), Cytosolic Invertase (B) and Bound cell Invertase (C) in grains. The correlation is significant at the $0.1 \%$ level. Each point is the mean of three observations 


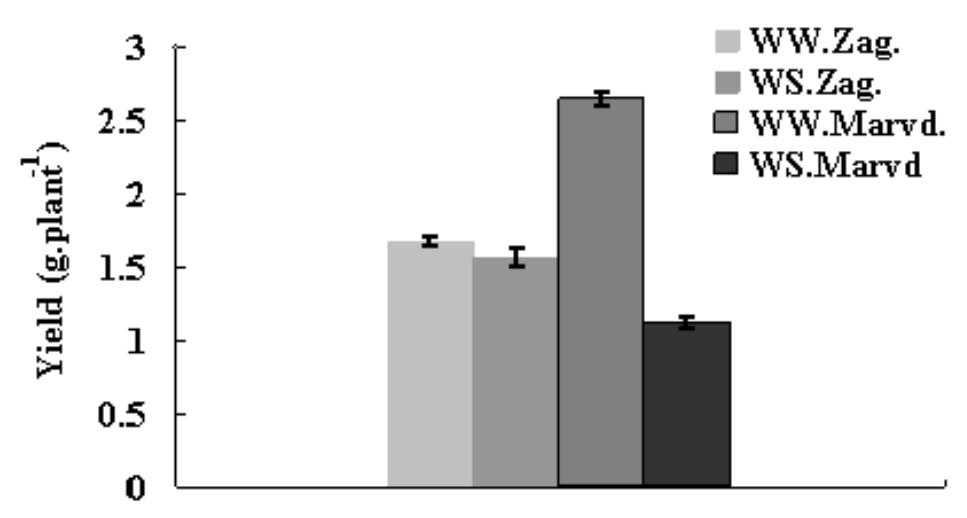

Figure 6. Grain yield per plant in well-watered (WW) or water-stressed (WS) treatment during grain filling in two wheat cultivars (drought sensitive cv. Marvdasht and drought Tolerant cv. Zagros). Vertical bars represent \pm $\mathrm{SE}$ of the mean $(\mathrm{n}=3)$ 